\title{
Vascular Response to Graded Angiotensin II Infusion in Offspring Subjected to High-Salt Drinking Water during Pregnancy: The Effect of Blood Pressure, Heart Rate, Urine Output, Endothelial Permeability, and Gender
}

\author{
Zahra Pezeshki, ${ }^{1}$ Fatemeh Eshraghi-Jazi, ${ }^{1}$ and Mehdi Nematbakhsh ${ }^{1,2,3}$ \\ ${ }^{1}$ Water \& Electrolytes Research Center, Isfahan University of Medical Sciences, Isfahan 81745, Iran \\ ${ }^{2}$ Department of Physiology, Isfahan University of Medical Sciences, Isfahan 81745, Iran \\ ${ }^{3}$ Isfahan MN Institute of Basic \& Applied Sciences Research, Isfahan 81546, Iran \\ Correspondence should be addressed to Mehdi Nematbakhsh; nematbakhsh@med.mui.ac.ir
}

Received 28 December 2013; Revised 10 March 2014; Accepted 13 March 2014; Published 17 April 2014

Academic Editor: Aaron S. Dumont

Copyright (C) 2014 Zahra Pezeshki et al. This is an open access article distributed under the Creative Commons Attribution License, which permits unrestricted use, distribution, and reproduction in any medium, provided the original work is properly cited.

\begin{abstract}
Introduction. Rennin-angiotensin system and salt diet play important roles in blood pressure control. We hypothesized that the high-salt intake during pregnancy influences the degree of angiotensin-dependent control of the blood pressure in adult offspring. Methods. Female Wistar rats in two groups (A and B) were subjected to drink tap and salt water, respectively, during pregnancy. The offspring were divided into four groups as male and female offspring from group A (groups 1 and 2) and from group B (groups 3 and 4). In anesthetized matured offspring mean arterial pressure (MAP), heart rate and urine output were measured in response to angiotensin II (AngII) $(0-1000 \mathrm{ng} / \mathrm{kg} / \mathrm{min}$, iv) infusion. Results. An increase in MAP was detected in mothers with salt drinking water $(P<0.05)$. The body weight increased and kidney weight decreased significantly in male offspring from group 3 in comparison to group $1(P<0.05)$. MAP and urine volume in response to AngII infusion increased in group $3(P<0.05)$. These findings were not observed in female rats. Conclusion. Salt overloading during pregnancy had long-term effects on kidney weight and increased sex-dependent response to AngII infusion in offspring (adult) that may reveal the important role of diet during pregnancy in AngII receptors.
\end{abstract}

\section{Introduction}

Normal pregnancy is associated with large changes in function and anatomy of cardiovascular system. Occasionally, pregnancy is accompanied by a condition called preeclampsia, which is characterized by edema, increased intravascular coagulation, proteinuria, increased systemic vascular resistance, and hypertension. Pregnancy-induced hypertension is a major cause of maternal and fetal mortality [1-3]. Highsalt intake is also often associated with increased vascular resistance and arterial pressure [3-5]. It is reported that arterial blood pressure was significantly higher in pregnant rats with high-salt intake in comparison with pregnant rats having normal-salt diet $[3,6,7]$. Maternal nutritional status during pregnancy has an important role in fetal growth $[8,9]$.
Furthermore, the risk of hypertension, as well as renal and cardiovascular diseases, is in part determined before birth by intrauterine factors [10]. Salt-supplemented diets cause higher sodium concentrations in the amniotic fluid in pregnant females. Lactating mothers with high-salt intake may produce milk with normal sodium concentration [7]. However, findings of previous studies indicate that the milk content in lactating mothers with high-salt intake altered [11]. Different salt diets may be recommended for blood pressure control during pregnancy as different levels of salt in utero lead to long-term consequences for health of the fetus or offspring [10]. Many systems involved in blood pressure control such as nephrogenesis, angiotensinogen expression, and renin formation are developed in early stages of pregnancy $[10,12,13]$. The salt diet may disturb these systems. 
Higher blood pressure was observed in offspring from mothers subjected to high-sodium intake during pregnancy and lactation $[7,10,14,15]$. Also, prenatally sodiumoverloaded pups showed disturbances in renal development, which leads to functional and structural alterations that persist in adult life [15]. These disturbances were associated with lower plasma levels of angiotensin II (AngII), changes in renal AngII receptor type 1 (AT1R) [10], and increased urinary protein [15]. Prenatal and postnatal sodium-overloaded rats showed increased urinary protein and kidney oxidative stress, reduced glomerular filtration rate (GFR), and increased plasma volume [15].

Renin angiotensin system plays an important role in blood pressure control, and its activity was reported to be gender-related [16-21]. The main arm of RAS is angiotensin II (AngII) which plays a role in the progression of kidney disease and its activity is influenced by AT1R and AT2R $[22,23]$. AT1R stimulation leads to vasoconstriction and reduction in GFR $[23,24]$. In addition, in response to AngII, AT2R leads to vasodilatation $[23,25]$. AT1R and AT2R expression in male and female are gender-dependent. The AT1R/AT2R ratio has also been examined in kidneys, and it is found to be lower in females because of the presence of $17 \beta$-estradiol [23-25].

Accordingly, it is hypothesized that different salt diets may influence renin angiotensin system or renal function in offspring. To test this hypothesis, adult male and female offspring from the mothers that received high-salt drinking water during pregnancy were subjected to AngII infusion and the blood pressure response was determined.

\section{Methods}

2.1. Animals. Eight female Wistar rats were individually housed in cages with temperature controlled at about $25^{\circ} \mathrm{C}$ and maintained with ad libitum standard rat diet in a 12hour light/dark cycle. The rats were randomly divided into two groups. Rats were maintained on tap water (group A) and high-salt water (2\%) (group B) before mating until delivery. High-salt water was prepared as 20 grams of salt in one liter of water. Pregnant female rats were carefully monitored at the end of pregnancy to determine the exact date of birth. On the day of weaning (30th day of life), mothers were prepared for surgery, and offspring were divided into four groups as described in the following.

Groups 1 and 2 are male (group 1) and female (group 2) offspring from mothers who received tap water during pregnancy.

Groups 3 and 4 are male (group 3) and female (group 4) offspring from mothers who received high-salt water during pregnancy.

All offspring in the aforementioned four groups were weighed in days 30, 45, and 60 after birth. Finally, these animals (called offspring (adult)) with the mean age of $70.2 \pm 1.08$ days were subjected to experimental procedures. All the animal experimental procedures described in this study were approved in advance by the Isfahan University of Medical Sciences Ethics Committee.

2.2. Drugs. The sodium chloride was purchased from Merck KGaA (Darmstadt, Germany); angiotensin II and Evans Blue were obtained from Sigma (St. Louis, Missouri, USA).

\section{Experimental Protocol}

3.1. Maternal Experimental Protocol. Thirty days after delivery, mothers in groups A and B were anesthetized with ketamine $(75 \mathrm{mg} / \mathrm{kg}$, ip), the trachea was cannulated to facilitate ventilation, and a catheter was implanted into the carotid artery. After basic stabilization for 30-60 min, blood pressure was measured and then blood sample was collected.

3.2. Offspring (Adult) Experimental Protocol. In experimental groups 1 to 4 , the animals were weighed and anesthetized with urethane $(1.5 \mathrm{~g} / \mathrm{kg})$. The trachea was isolated to insert an air ventilation tube. Then, the carotid artery was cannulated to record blood pressure and jugular vein was cannulated for AngII infusion. A catheter was implanted into the bladder to measure urine volume. Urine output was collected online during AngII infusion for period of one hour. After surgical procedures, basal blood sample $(0.5 \mathrm{~mL})$ was collected from the carotid artery and then centrifuged at $6000 \mathrm{~g}$ for $20 \mathrm{~min}$ to determine serum levels of nitrite (stable NO metabolite) and $\mathrm{Na}^{+}$; then, after the equilibrium time (30-60 min), direct blood pressure was continuously monitored. Then, a series of intravenous infusions of AngII (0,30, 100, and $300 \mathrm{ng}$ $\mathrm{kg}^{-1} \min ^{-1}$ ) via the jugular vein was commenced. Each dose was administered until arterial blood pressure equilibration was achieved (in about a $10 \mathrm{~min}$ period), and then the measurements were performed for 3-5 minutes. At the end of the study, Evans Blue [9] solution (10 mg/kg) was injected via the carotid artery, and, one hour later, all animals were sacrificed by a lethal injection of intravenous potassium chloride (10\% KCL).

\section{Measurements}

The level of nitrite was measured using a colorimetric assay kit (Promega Corporation, USA) that involved the Griess reaction. Briefly, after adding sulfanilamide solution and after incubation, N-(1-naphthyl)ethylenediamine solution was added. Next, the sample absorbance was measured by a microreader in the wavelength of $492 \mathrm{~nm}$. The nitrite concentration of samples was determined by comparing with the nitrite standard reference curve. The serum level of $\mathrm{Na}^{+}$ was also measured by a flame photometer.

4.1. Determination of Aortic Endothelial Permeability. Endothelial permeability of the aorta was measured by the EB method. Briefly, one hour after EB injection, a piece of thoracic aorta was obtained and immediately weighed. Then, 2 cc formamide (Merck, Germany) was added and placed in an oven $\left(80^{\circ} \mathrm{C}\right)$ for 24 hours. After cooling, the absorbance was measured at $623 \mathrm{~nm}$. The standard curve 
TABLE 1: Number of newborns, MAP, and serum nitrite level of mother with salt and tap water 30 days after delivery.

\begin{tabular}{lcccccc}
\hline Group & \multicolumn{3}{c}{ Number of newborns } & MAP $(\mathrm{mmHg})$ & Nitrite $(\mu \mathrm{mole} / \mathrm{Lit})$ & $\mathrm{Na}{ }^{+}(\mathrm{meq} / \mathrm{Lit})$ \\
& Total & male & female & $101.6 \pm 2.6$ & $35.2 \pm 7.5$ & $135.7 \pm 3.9$ \\
A & $9.7 \pm 1.2$ & $6 \pm 1.5$ & $3.7 \pm 1.1$ & $113.8 \pm 3.8^{*}$ & $12.3 \pm 1.9^{*}$ & $175.7 \pm 14.8^{*}$ \\
B & $6.5 \pm 1.3$ & $2.7 \pm 0.2^{*}$ & $3.7 \pm 1.0$ & 0.039 & 0.025 & 0.076 \\
$P$ value & 0.137 & 0.046 & 0.770 & & \\
\hline
\end{tabular}

${ }^{*}$ Significantly different from group A.

TABLE 2: Basal values of MAP, HR, serum nitrite, $\mathrm{Na}^{+}$, and aorta permeability in male and female offspring (adult). Groups 1 and 2: male (group 1) and female (group 2) offspring from mothers who received tap water during pregnancy. Groups 3 and 4: male (group 3) and female (group 4) offspring from mothers who received high-salt water during pregnancy.

\begin{tabular}{|c|c|c|c|c|c|c|}
\hline Gender & Group & $\begin{array}{c}\text { Basal MAP } \\
(\mathrm{mmHg})\end{array}$ & $\begin{array}{c}\text { Basal HR } \\
\text { (beat/min) }\end{array}$ & $\begin{array}{c}\text { Basal serum } \\
\text { nitrite } \\
(\mu \mathrm{mol} / \mathrm{Lit}) \\
\end{array}$ & $\begin{array}{c}\text { Aorta } \\
\text { permeability } \\
(\mu \mathrm{g} / \mathrm{gr} \text { tissue })\end{array}$ & $\mathrm{Na}^{+}$(meq/Lit) \\
\hline \multirow{2}{*}{ Male } & 1 & $115.3 \pm 2.5$ & $365 \pm 14$ & $4.71 \pm 1.31$ & $23.32 \pm 4.49$ & $132.75 \pm 4.44$ \\
\hline & 3 & $106.2 \pm 7.1$ & $371 \pm 15$ & $11.74 \pm 3.94$ & $19.66 \pm 4.35$ & $133.5 \pm 2.23$ \\
\hline \multicolumn{2}{|c|}{$P$ value } & 0.261 & 0.775 & 0.154 & 0.572 & 0.871 \\
\hline \multirow{3}{*}{ Female } & 2 & $98.1 \pm 8.8$ & $380 \pm 6$ & $8.33 \pm 2.92$ & $20.51 \pm 5.09$ & $133 \pm 2.38$ \\
\hline & 4 & $100.9 \pm 6.4$ & $379 \pm 17$ & $5.65 \pm 0.59$ & $21.37 \pm 6.20$ & $136 \pm 2.81$ \\
\hline & $P$ value & 0.810 & 0.987 & 0.436 & 0.915 & 0.457 \\
\hline
\end{tabular}

of EB concentration was plotted and the EB concentration $(\mu \mathrm{g})$ to aorta weight (gr) was determined as the endothelial permeability.

4.2. Serum Volume Measurement. Serum volume was measured using EB [26]. Sixty minutes after administration of EB, blood samples were collected and centrifuged. The dye concentration in the removed serum was determined at $623 \mathrm{~nm}$ and compared to a standard curve constructed using determined concentrations of the EB dye. The EB concentration was calculated according to the amount of EB injected to each animal and finally the serum volume was measured.

4.3. Statistical Analysis. Data were expressed as mean \pm SEM. Body weight and MAP and heart rate (HR) response to AngII were compared via repeated measures ANOVA for different groups of factors and doses $\left(0,30,100\right.$, and $300 \mathrm{ng} \mathrm{kg}^{-1}$ $\mathrm{min}^{-1}$ AngII) and their interactions. The $P$ value $<0.05$ was considered statistically significant. The Student's $t$-test was used to compare other factors between the groups. Mothers in groups $\mathrm{A}$ and $\mathrm{B}$ were compared in the number of newborn via Mann-Whitney values.

\section{Results}

All measurements were in anesthetized rats. Therefore the findings related to blood pressure may not be reflective of physiological blood pressure levels, but the conditions were similar in all groups.

5.1. Maternal Data. Maternal data are shown in Table 1. The data indicated that the number of male newborns in group A (mothers received tap water during pregnancy) was statistically greater than that in group $\mathrm{B}(P<0.05)$. In group B, higher MAP and serum $\mathrm{Na}^{+}$levels, and lower serum nitrite level were obtained, indicating that the salt diet during pregnancy increased MAP 30 days after delivery.

\subsection{Offspring (Adult) Data}

5.2.1. MAP, HR, and Urine Volume Change in response to AngII Infusion. The basal data demonstrated no significant difference between the two groups of male (groups 1 and 3 ) and the two groups of female animals (groups 2 and 4) (Table 2). Results in the male offspring indicate that MAP, urine volume, and HR in response to AngII were significantly higher in group 3 than those in group1 $(P<0.05)$. Such observation was not detected in female animals (Figures 1 and 2).

5.2.2. Serum Levels of Nitrite and Sodium and Aorta Endothelial Permeability. Serum nitrite level in group 3 was greater than that in group 1, but the difference was not statistically significant. The groups were not significantly different with regard to the serum level of $\mathrm{Na}^{+}$and endothelial permeability of aorta as EB uptake (Table 2).

5.2.3. Body Weight, Kidney Weight, and Serum Volume. Changes of body weight in days 30, 45, and 60 after birth showed significant weight gain in group 3 when compared with group $1(P<0.05)$ (Figure 1$)$. Also, serum volume in group 3 was higher than the volume in the other group $(P<0.05)$. However, kidney weight (KW g/100 g body weight) in group 3 was significantly less than that in group 1 $(P<0.05)$. Such finding was not observed in female groups 2 and 4 (Figure 2). 
Male
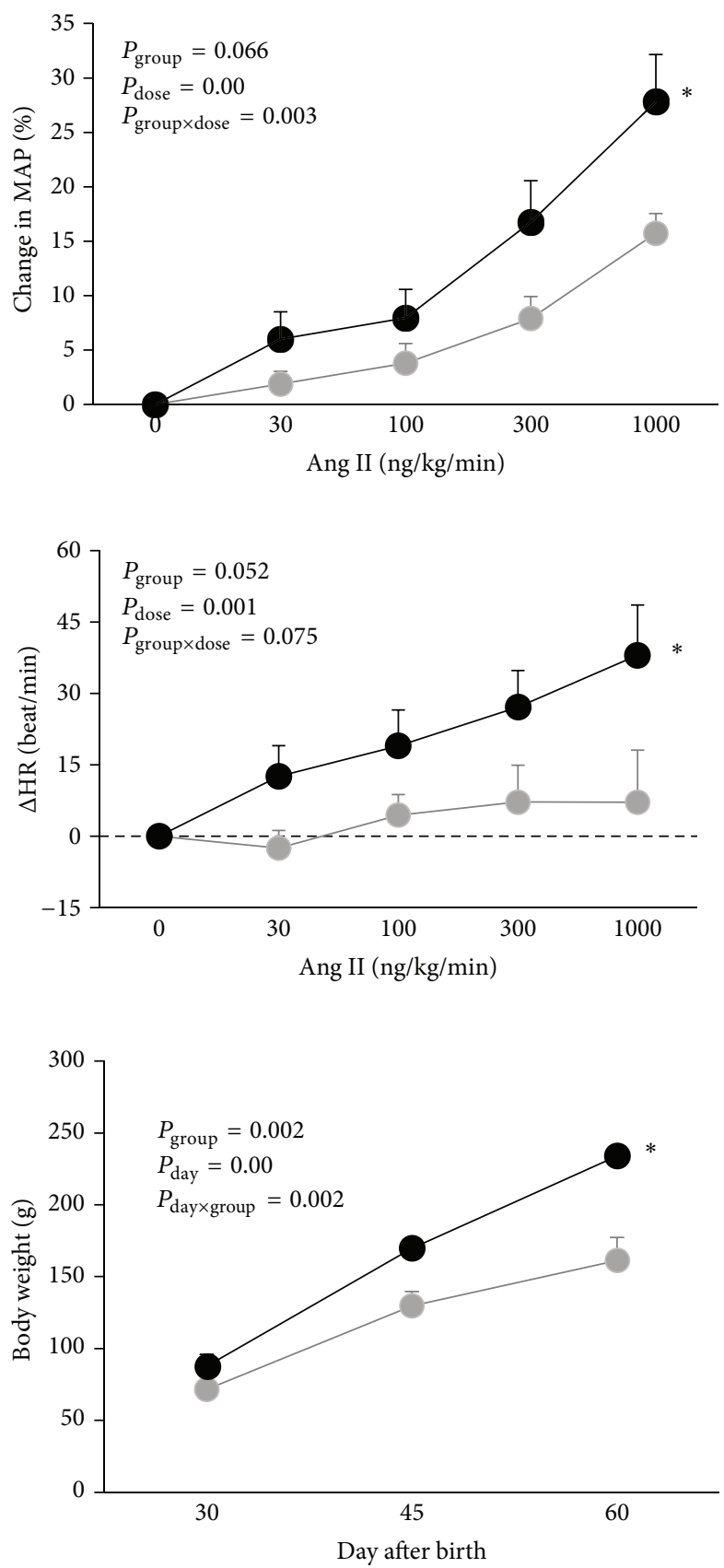

Group 1

Group 3
Female
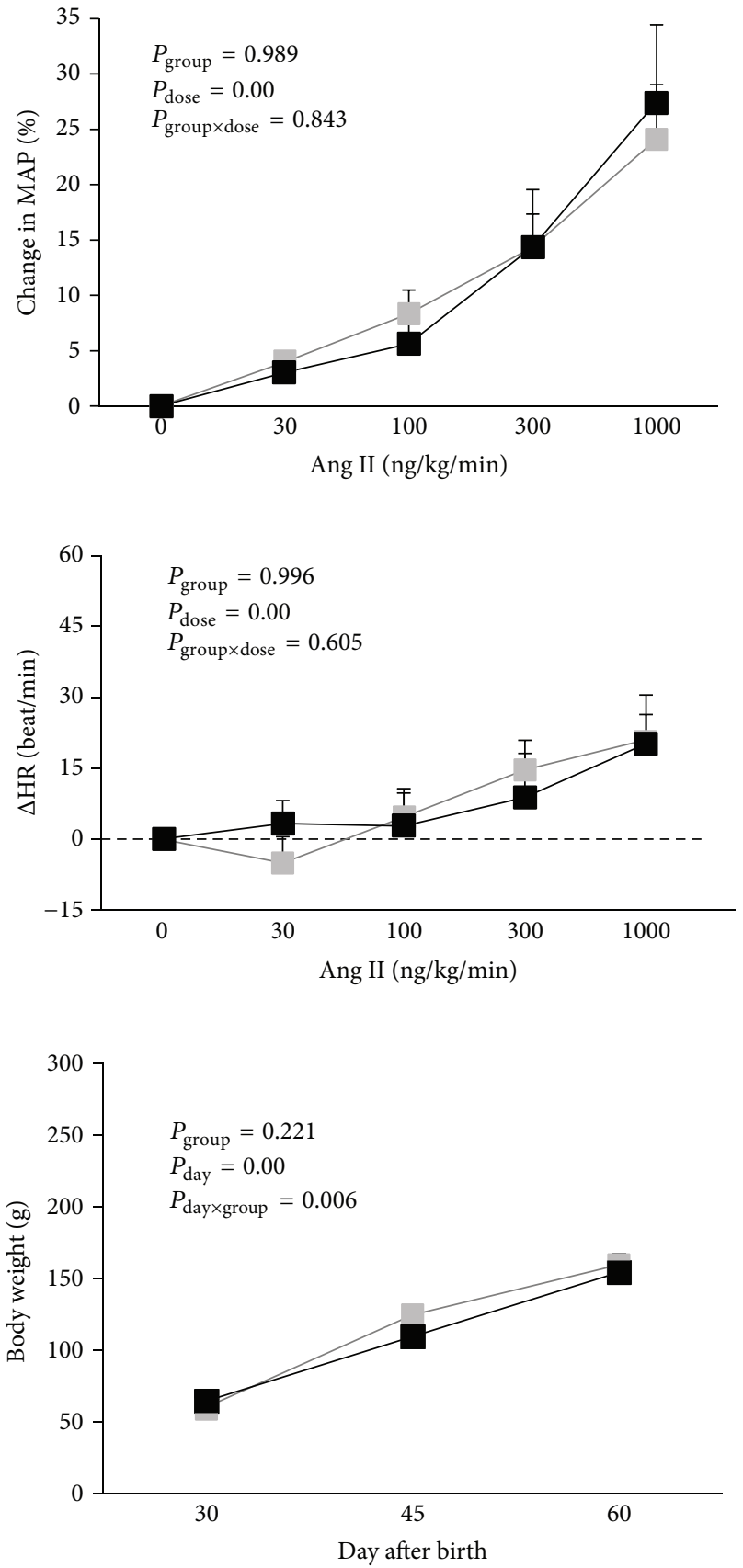

Group 2

Group 4

FIGURE 1: MAP and HR responses to AngII and body weight change in male (groups 1 and 3) and female (groups 2 and 4 ) offspring (adult). The star $(*)$ indicates significant difference from group 1. Groups 1 and 2: male (group 1) and female (group 2) offspring from mothers who received tap water during pregnancy. Groups 3 and 4: male (group 3) and female (group 4) offspring from mothers who received high-salt water during pregnancy.

\section{Discussion}

The major findings of this study indicated that highsalt intake during pregnancy decreased kidney weight and increased plasma volume and increased the vascular, heart, and urine output responses to graded AngII infusion in male but not in female adult offspring. It is well known that salt diet is accompanied with increased vascular resistance and arterial pressure [3-5], and it increases arterial blood pressure in pregnant rats $[3,6,7]$. Higher blood 

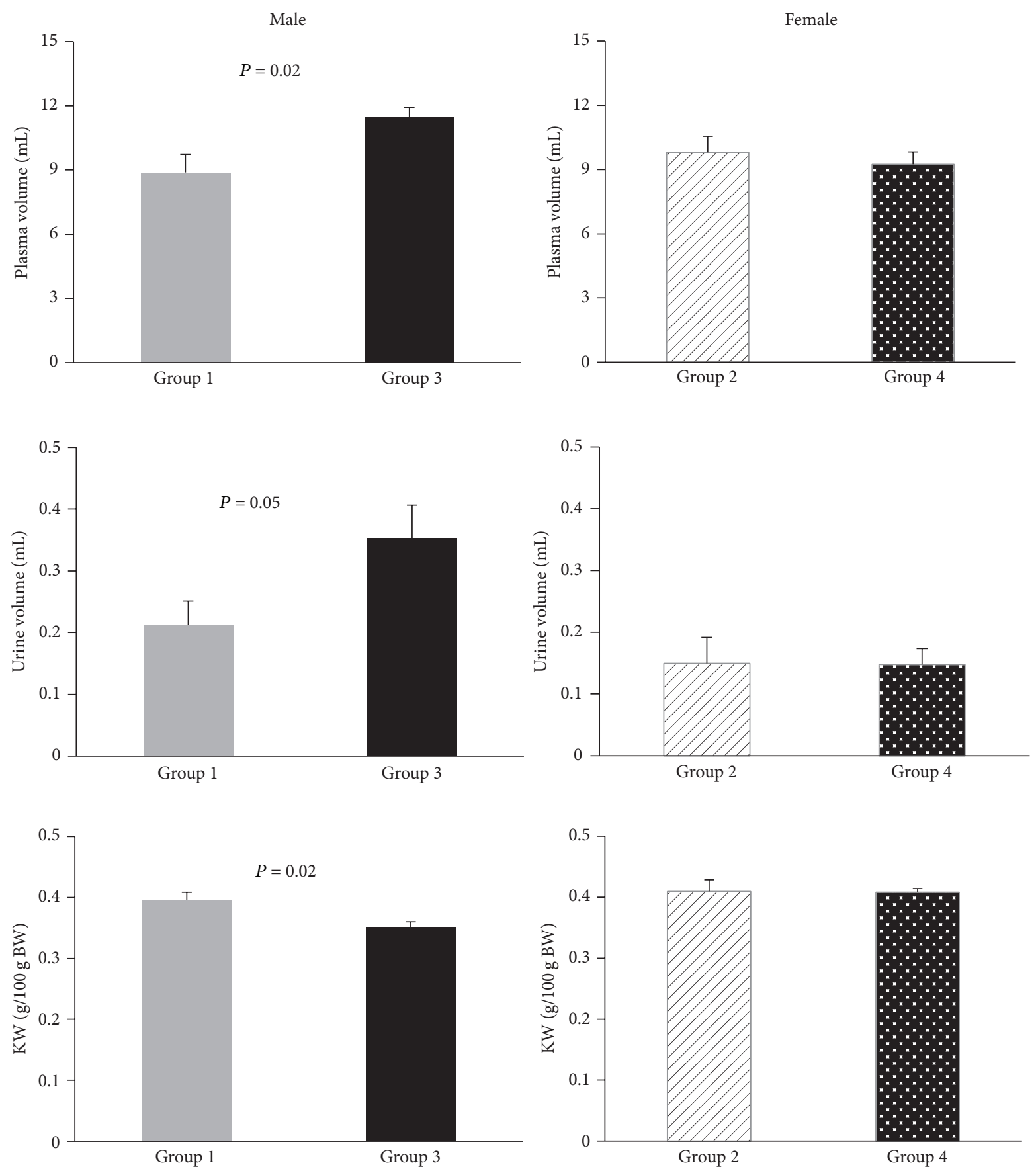

FIGURE 2: Body weight, urine output response to AngII infusion, and kidney weight in male (groups 1 and 3) and female (groups 2 and 4) offspring (adult). Groups 1 and 2: male (group 1) and female (group 2) offspring from mothers who received tap water during pregnancy. Groups 3 and 4: male (group 3) and female (group 4) offspring from mothers who received high-salt water during pregnancy.

pressure was observed in offspring from mothers subjected to high-sodium intake during pregnancy and lactation $[7$, $10,14,15]$, and certainly maternal nutritional status during pregnancy plays an important role in fetal growth $[8,9]$ and organ function. It seems that, among the factors that provide hypertension in offspring from mothers subjected to high-sodium intake during pregnancy, RAS is the main controlling system. Recently, Bayoglu et al. demonstrated that angiotensinogen, angiotensin converting enzyme [27], AT1R, and AT2R expression altered following maternal high-salt intake. They suggested that high-salt diet during pregnancy affects expression of the renal key elements of RAS in fetus and offspring [28]. The effect of low- and high-salt diets during pregnancy was examined on heart of male offspring, and it was concluded that high-salt diet in adult male offspring leads to higher levels of blood pressure and 
angiotensin II [29]. Although adaptive response to salt during pregnancy is also important for offspring [30], it is not exactly clear how other functional systems may be disturbed from this salt diet. Reduction in number of glomeruli and higher risk of hypertension may occur in offspring from mothers who were subjected to high-salt diet during pregnancy [31]. High-salt intake during pregnancy was investigated in other studies, indicating that cardiac cell and RAS may be disturbed in offspring [32,33], but gender difference is not exactly known. Our findings also demonstrated that high-salt diet during pregnancy increased the MAP response to AngII only in male rats. However, this was not observed in female rats. It is reported that females compared with males are less sensitive to AngII $[25,34,35]$. Sensitivity to AngII is mediated by AT2R [35] and AT2R/AT1R expression ratio, which is also higher in female than male $[36,37]$. It is important that when the endogenous RAS is blocked, males are still more sensitive to salt diets [38]. Accordingly, there is a possibility that highsalt diets in pregnant rats may alter the AT1R expression in male offspring but not in female. Urine volume response to AngII was also increased in male offspring from mothers who received high-salt diet, while urine volume generally decreased in these offspring [28]. The results obtained for the kidney weight in the current study were inconsistence with the results reported in other experiments [28]. Finally, significant difference was observed in serum nitrite level of mothers with salt and tap water 30 days after delivery, but no difference was observed between offspring (adults). Nitric oxide concentration is related to endothelial function [39-42]. Endothelial cells are salt sensor, and endothelial function could be changed by salt intake [43-46] because salt inactivates endothelial NO synthase in endothelial cell [47]. Therefore, the reduction of serum nitrite level in mothers with salt water is directly related to salt intake.

\section{Conclusion}

High-salt intake during pregnancy promotes MAP, heart rate, and urine output responses to AngII in male offspring. Increase in body weight and plasma volume and decrease in kidney weight were also observed in such male offspring. High-salt drinking water during pregnancy may not alter MAP, heart rate, and urine output response to AngII in female offspring. The results obtained suggest the effect of salt drinking water during pregnancy in development of RAS in male offspring.

\section{Conflict of Interests}

The authors declare that there is no conflict of interests regarding the publication of this paper.

\section{Acknowledgment}

This research was supported by Isfahan University of Medical Sciences (Grant no. 292131).

\section{References}

[1] W. Ganzevoort, A. Rep, G. J. Bonsel, J. I. P. de Vries, and H. Wolf, "Plasma volume and blood pressure regulation in hypertensive pregnancy," Journal of Hypertension, vol. 22, no. 7, pp. 1235-1242, 2004.

[2] J. B. Giardina, K. L. Cockrell, J. P. Granger, and R. A. Khalil, "Low-salt diet enhances vascular reactivity and $\mathrm{Ca}^{2+}$ entry in pregnant rats with normal and reduced uterine perfusion pressure," Hypertension, vol. 39, no. 2, part 2, pp. 368-374, 2002.

[3] L. A. Barron, J. B. Giardina, J. P. Granger, and R. A. Khalil, "High-salt diet enhances vascular reactivity in pregnant rats with normal and reduced uterine perfusion pressure," Hypertension, vol. 38, no. 3, part 2, pp. 730-735, 2001.

[4] L. H. Kuller, "Salt and blood pressure: population and individual perspectives," American Journal of Hypertension, vol. 10, no. 5, part 2, pp. 29S-36S, 1997.

[5] L. Tobian, "Salt and hypertension. Lessons from animal models that relate to human hypertension," Hypertension, vol. 17, no. 1, supplement, pp. I52-I58, 1991.

[6] C. P. Aloamaka, M. Ezimokhai, N. A. Osman, and J. Morrison, "The mechanism of relaxation in response to magnesium by the aorta of pregnant rats with salt-induced hypertension," Experimental Physiology, vol. 80, no. 1, pp. 79-87, 1995.

[7] N. Hazon, C. Parker, R. Leonard, and I. W. Henderson, "Influence of an enriched dietary sodium chloride regime during gestation and suckling and post-natally on the ontogeny of hypertension in the rat," Journal of Hypertension, vol. 6, no. 7, pp. 517-524, 1988.

[8] H. Okubo, Y. Miyake, S. Sasaki, K. Tanaka, K. Murakami, and Y. Hirota, "Dietary patterns during pregnancy and the risk of postpartum depression in Japan: the Osaka Maternal and Child Health Study," British Journal of Nutrition, vol. 105, no. 8, pp. 1251-1257, 2011.

[9] C. Rodriguez-Bernal, M. Rebagliato, and F. Ballester, "Maternal nutrition and fetal growth: the role of iron status and intake during pregnancy," Nutrition, vol. 2012, pp. 25-37, 2012.

[10] T. M. Coimbra, H. D. Francescato, A. P. Balbi, E. C. Marin, and R. S. Costa, "Renal development and blood pressure in offspring from dams submitted to high-sodium intake during pregnancy and lactation," International Journal of Nephrology, vol. 2012, Article ID 919128, 5 pages, 2012.

[11] M. Vijande, J. I. Brime, P. López-Sela, M. Costales, and J. Argüelles, "Increased salt preference in adult offspring raised by mother rats consuming excessive amounts of salt and water," Regulatory Peptides, vol. 66, no. 1-2, pp. 105-108, 1996.

[12] A. P. C. Balbi, R. S. Costa, and T. M. Coimbra, "Postnatal renal development of rats from mothers that received increased sodium intake," Pediatric Nephrology, vol. 19, no. 11, pp. 12121218,2004

[13] R. A. Gomez, "Molecular biology of components of the reninangiotensin system during development," Pediatric Nephrology, vol. 4, no. 4, pp. 421-423, 1990.

[14] E. C. S. Marin, A. P. C. Balbi, H. D. C. Francescato, C. G. Alves da Silva, R. S. Costa, and T. M. Coimbra, "Renal structure and function evaluation of rats from dams that received increased sodium intake during pregnancy and lactation submitted or not to 5/6 nephrectomy," Renal Failure, vol. 30, no. 5, pp. 547-555, 2008.

[15] H. D. Cardoso, E. V. Cabral, L. D. Vieira-Filho, A. Vieyra, and A. D. O. Paixão, "Fetal development and renal function in adult rats 
prenatally subjected to sodium overload," Pediatric Nephrology, vol. 24, no. 10, pp. 1959-1965, 2009.

[16] T. Safari and M. Nematbakhsh, "Angiotensin 1-7 receptor and angiotensin II receptor 2 blockades prevent the increased serum and kidney nitric oxide levels in response to angiotensin II administration: gender-related difference," International Journal of Preventive Medicine, vol. 4, no. 3, pp. 311-315, 2013.

[17] Y. F. Zhang, Q. Cheng, N. L. Tang et al., "Gender difference of serum angiotensin-converting enzyme (ACE) activity in DD genotype of ACE insertion/deletion polymorphism in elderly Chinese," Journal of the Renin-Angiotensin-Aldosterone System, 2013.

[18] A. I. Rodriguez-Perez, R. Valenzuela, B. Joglar, P. Garrido-Gil, M. J. Guerra, and J. L. Labandeira-Garcia, "Renin angiotensin system and gender differences in dopaminergic degeneration," Molecular Neurodegeneration, vol. 6, no. 1, article 58, 2011.

[19] L. M. Hilliard, M. Nematbakhsh, M. M. Kett et al., "Gender differences in pressure-natriuresis and renal autoregulation: role of the angiotensin type 2 receptor," Hypertension, vol. 57, no. 2, pp. 275-282, 2011.

[20] P. Zapater, J. Novalbos, S. Gallego-Sandín, F. T. Hernández, and F. Abad-Santos, "Gender differences in angiotensin-converting enzyme (ACE) activity and inhibition by enalaprilat in healthy volunteers," Journal of Cardiovascular Pharmacology, vol. 43, no. 5, pp. 737-744, 2004.

[21] S. B. Lall, S. S. Peshin, and M. G. Karmarkar, "Plasma renin activity in normal healthy volunteers: effect of physiological variables," Indian Journal of Physiology and Pharmacology, vol. 39, no. 1, pp. 51-54, 1995.

[22] S. R. Silbiger and J. Neugarten, "The impact of gender on the progression of chronic renal disease," American Journal of Kidney Diseases, vol. 25, no. 4, pp. 515-533, 1995.

[23] I. Armando, M. Jezova, A. V. Juorio et al., "Estrogen upregulates renal angiotensin II AT2 receptors," American Journal of Physiology-Renal Physiology, vol. 283, no. 5, pp. F934-F943, 2002.

[24] G. Nickenig, A. T. Bäumer, C. Grohè et al., "Estrogen modulates AT1 receptor gene expression in vitro and in vivo," Circulation, vol. 97, no. 22, pp. 2197-2201, 1998.

[25] J. C. Sullivan, "Sex and the renin-angiotensin system: inequality between the sexes in response to RAS stimulation and inhibition," American Journal of Physiology-Regulatory Integrative and Comparative Physiology, vol. 294, no. 4, pp. R1220-R1226, 2008.

[26] J. Farjanel, C. Denis, J. C. Chatard, and A. Geyssant, "An accurate method of plasma volume measurement by direct analysis of Evans blue spectra in plasma without dye extraction: origins of albumin-space variations during maximal exercise," European Journal of Applied Physiology, vol. 75, no. 1, pp. 75-82, 1997.

[27] B. Bayoglu, M. Cengiz, G. Karacetin et al., "Genetic polymorphism of angiotensin I-converting enzyme (ACE), but not angiotensin II type i receptor (ATr1), has a gender-specific role in panic disorder," Psychiatry and Clinical Neurosciences, vol. 66, no. 2, pp. 130-137, 2012.

[28] C. Mao, R. Liu, L. Bo et al., "High-salt diets during pregnancy affected fetal and offspring renal renin-angiotensin system," The Journal of Endocrinology, vol. 218, no. 1, pp. 61-73, 2013.

[29] E. N. Alves-Rodrigues, M. M. Veras, K. T. Rosa et al., "Salt intake during pregnancy alters offspring's myocardial structure," Nutrition, Metabolism and Cardiovascular Diseases, vol. 23, no. 5, pp. 481-486, 2013.
[30] S. N. Digby, M. A. Chadwick, and D. Blache, "Salt intake and reproductive function in sheep," Animal, vol. 5, no. 8, pp. 12071216, 2011.

[31] N. Koleganova, G. Piecha, E. Ritz et al., "Both high and low maternal salt intake in pregnancy alter kidney development in the off spring," American Journal of Physiology-Renal Physiology, vol. 301, no. 2, pp. F344-F354, 2011.

[32] Y. Ding, J. Lv, C. Mao et al., "High-salt diet during pregnancy and angiotensin-related cardiac changes," Journal of Hypertension, vol. 28, no. 6, pp. 1290-1297, 2010.

[33] A. Alves da Silva, I. L. de Noronha, I. B. de Oliveira, D. M. C. Malheiros, and J. C. Heimann, "Renin-angiotensin system function and blood pressure in adult rats after perinatal salt overload," Nutrition, Metabolism and Cardiovascular Diseases, vol. 13, no. 3, pp. 133-139, 2003.

[34] J. C. Sullivan, K. Bhatia, T. Yamamoto, and A. A. Elmarakby, "Angiotensin (1-7) receptor antagonism equalizes angiotensin II-induced hypertension in male and female spontaneously hypertensive rats," Hypertension, vol. 56, no. 4, pp. 658-666, 2010.

[35] A. K. Sampson, K. M. Moritz, E. S. Jones, R. L. Flower, R. E. Widdop, and K. M. Denton, "Enhanced angiotensin II type 2 receptor mechanisms mediate decreases in arterial pressure attributable to chronic low-dose angiotensin II in female rats," Hypertension, vol. 52, no. 4, pp. 666-671, 2008.

[36] M. M. Silva-Antonialli, R. C. A. Tostes, L. Fernandes et al., "A lower ratio of AT1/AT2 receptors of angiotensin II is found in female than in male spontaneously hypertensive rats," Cardiovascular Research, vol. 62, no. 3, pp. 587-593, 2004.

[37] R. D. Brown, L. M. Hilliard, G. A. Head, E. S. Jones, R. E. Widdop, and K. M. Denton, "Sex differences in the pressor and tubuloglomerular feedback response to angiotensin II," Hypertension, vol. 59, no. 1, pp. 129-135, 2012.

[38] J. C. Sartori-Valinotti, R. Iliescu, L. L. Yanes, W. Dorsett-Martin, and J. F. Reckelhoff, "Sex differences in the pressor response to angiotensin II when the endogenous renin-angiotensin system is blocked," Hypertension, vol. 51, no. 4, pp. 1170-1176, 2008.

[39] L. J. Ignarro and C. Napoli, "Novel features of nitric oxide, endothelial nitric oxide synthase, and atherosclerosis," Current Diabetes Reports, vol. 5, no. 1, pp. 17-23, 2005.

[40] A. J. Maxwell, "Mechanisms of dysfunction of the nitric oxide pathway in vascular diseases," Nitric Oxide, vol. 6, no. 2, pp. 101$124,2002$.

[41] C. Napoli, F. de Nigris, S. Williams-Ignarro, O. Pignalosa, V. Sica, and L. J. Ignarro, "Nitric oxide and atherosclerosis: an update," Nitric Oxide, vol. 15, no. 4, pp. 265-279, 2006.

[42] T. Rassaf, P. Kleinbongard, and M. Kelm, “The L-arginine nitric oxide pathway: avenue for a multiple-level approach to assess vascular function," Biological Chemistry, vol. 387, no. 10-11, pp. 1347-1349, 2006.

[43] M. A. Boegehold, “The effect of high salt intake on endothelial function: reduced vascular nitric oxide in the absence of hypertension," Journal of Vascular Research, vol. 50, no. 6, pp. 458-467, 2013.

[44] W. Z. Ying, K. J. Aaron, and P. W. Sanders, "Transforming growth factor- $\beta$ regulates endothelial function during high salt intake in rats," Hypertension, vol. 62, no. 5, pp. 951-956, 2013.

[45] K. M. Dickinson, P. M. Clifton, and J. B. Keogh, "Endothelial function is impaired after a high-salt meal in healthy subjects," American Journal of Clinical Nutrition, vol. 93, no. 3, pp. 500$505,2011$. 
[46] H. Oberleithner, K. Kusche-Vihrog, and H. Schillers, "Endothelial cells as vascular salt sensors," Kidney International, vol. 77, no. 6, pp. 490-494, 2010.

[47] J. Li, J. White, L. Guo et al., "Salt inactivates endothelial nitric oxide synthase in endothelial cells," Journal of Nutrition, vol. 139, no. 3, pp. 447-451, 2009. 


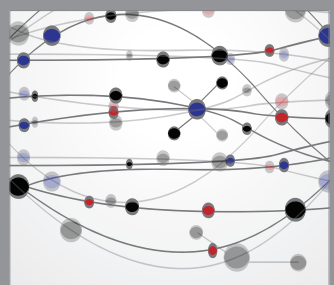

The Scientific World Journal
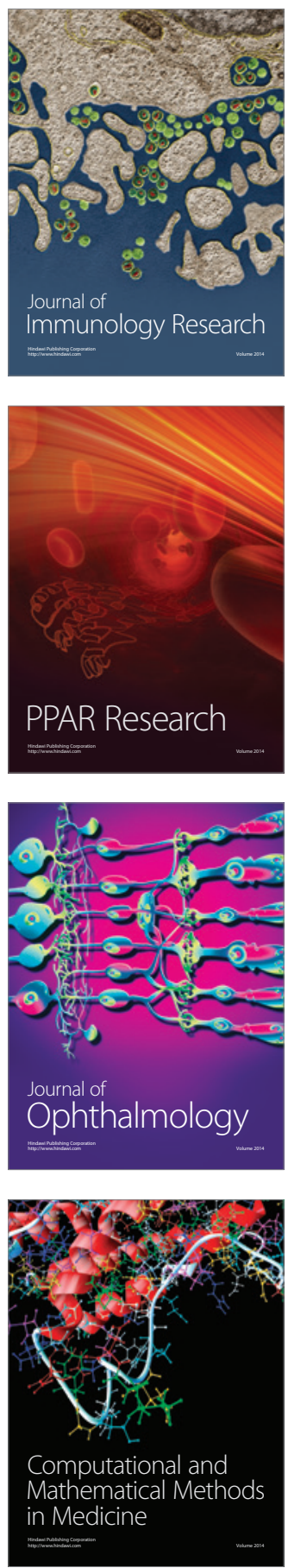

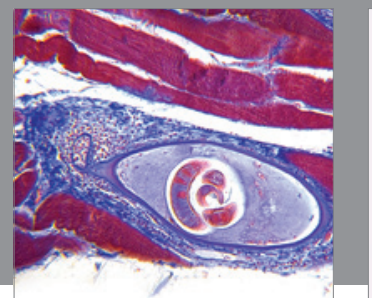

Gastroenterology

Research and Practice
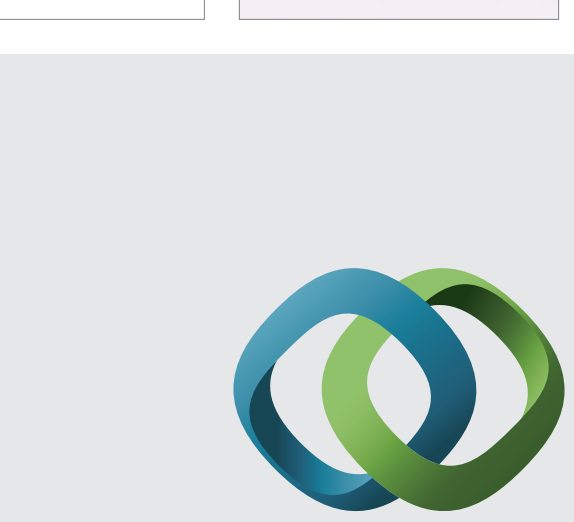

\section{Hindawi}

Submit your manuscripts at

http://www.hindawi.com
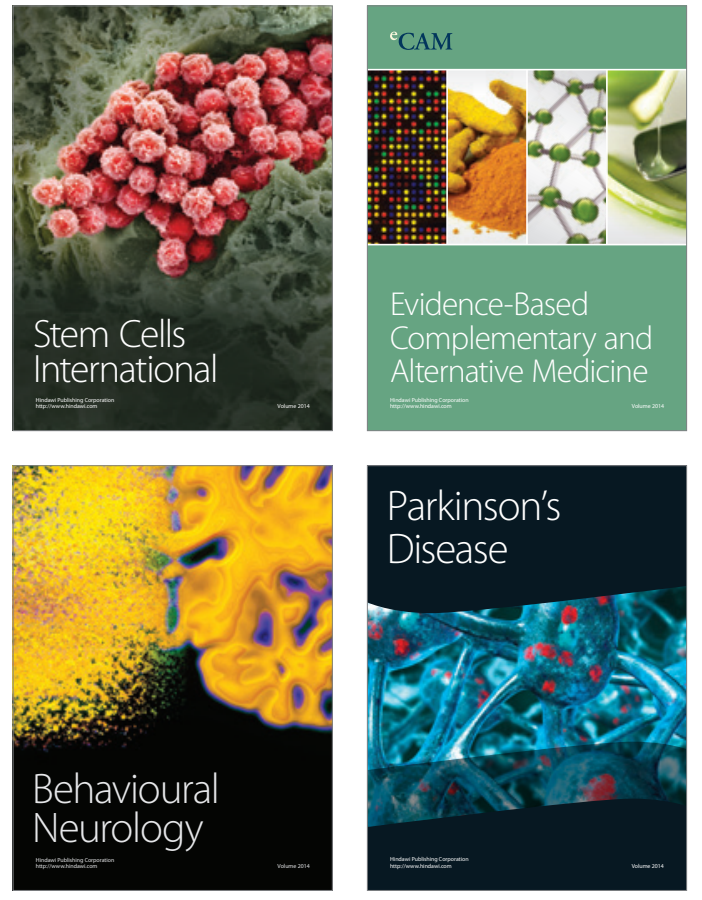
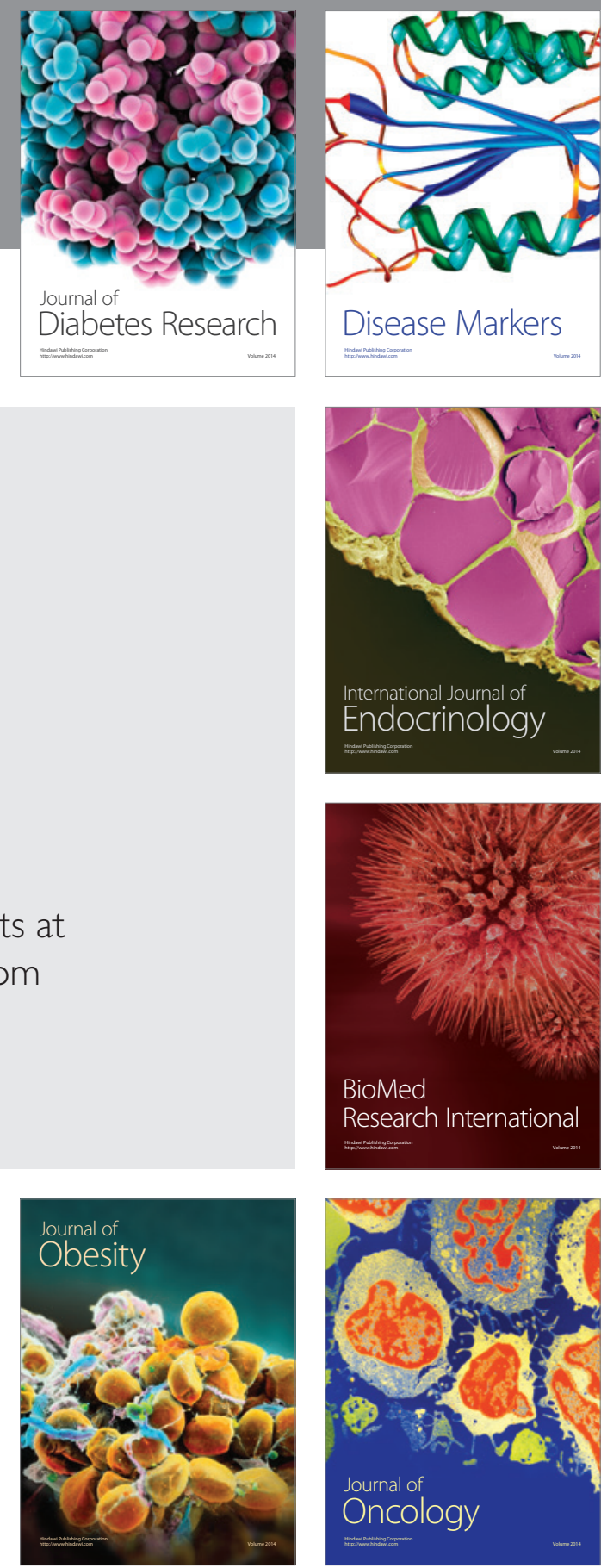

Disease Markers
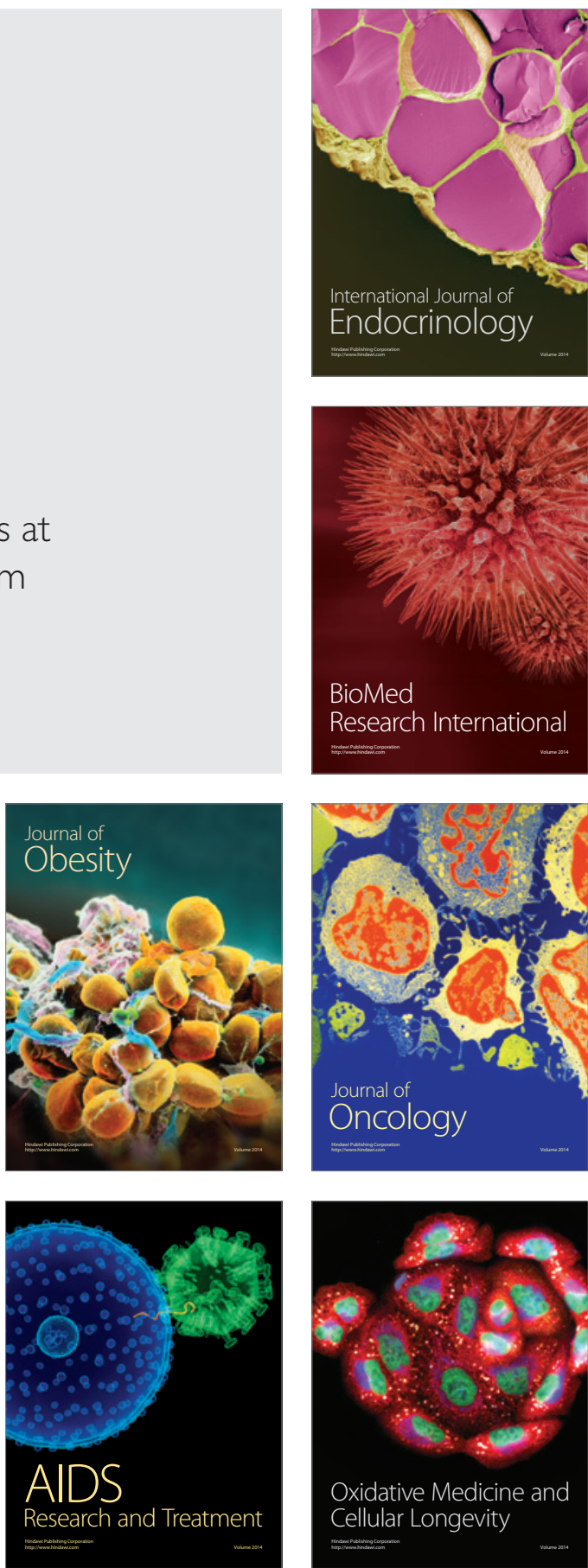